Ribeirão Preto, 10 de dezembro de 2004

\section{Triste órbita, ó quão dessemelhante...}

O título parafraseia um famoso poema de Gregório de Mattos (poeta baiano do século XVII), musicado na década de setenta por Caetano Veloso. O tom do poema é amargo, adequado ao tema dessa comunicação.

É impressionante, a conduta que alguns colegas oftalmologistas tomam em relação às patologias orbitárias. Esse assunto já foi tema de um editorial que escrevi para a Revista Brasileira de Oftalmologia e não pretendo ser repetitivo, mas não posso deixar de registrar a minha inconformidade quando vejo oftalmologistas encaminhando, sem nenhum critério, doenças orbitárias a neurocirurgiões.

Recentemente, recebi em minha clínica particular uma senhora, do interior do Brasil, de condição social humilde que, movida pelo calvário que estava vivendo a sua filha, fez um esforço extraordinário para vir a Ribeirão Preto e pagar uma consulta particular. Resumidamente, a história é a seguinte. Sua filha de 14 anos, apresentou durante cerca de 10 meses, dor e proptose moderada no olho esquerdo. Como o quadro estava piorando, procurou um oftalmologista que depois de inúmeras consultas e várias ultra-sonografias, solicitou um exame de ressonância magnética de órbitas e a encaminhou a um neurocirurgião.

O especialista em patologia do sistema nervoso central, pediu para a realização da cirurgia uma soma incompatível com a realidade socioeconômica da família. Devido a impossibilidade da cirurgia na rede privada, o colega a encaminhou ao Sistema Único de Saúde de sua cidade. Após meses de espera, a paciente finalmente conseguiu acesso a um serviço de neurocirurgia público em outra localidade (700 a 800 km de distância) onde finalmente foi operada. Para grande surpresa de todos (da mãe, da paciente e provavelmente do cirurgião) após uma operação de 10 horas o tumor não foi inteiramente retirado e o resultado do exame anátomo-patológico foi dado como inconclusivo, porque o cirurgião se esqueceu de fixar o material obtido da órbita. Após a paciente foi encaminhada a um oftalmologista para corrigir a ptose e o estrabismo induzidos pelo tratamento.

Semanas após a cirurgia, a paciente procurou o nosso serviço. Ao exame mostrava: $\mathrm{AV}$ : $\mathrm{OD}=1,0, \mathrm{OE}=0,5$, proptose desfigurante à esquerda, hipotropia e exotropia do OE. Nesse olho, a tomografia computadorizada de órbitas revela sinais inequívocos de retirada cirúrgica do teto da órbita e uma massa que preenchia todo o conteúdo orbitário e portanto estava adjacente ao lobo frontal esquerdo. Biópsia transconjuntival revelou um rabdomiossarcoma do tipo alveolar que é o subtipo de pior prognóstico.

Quase um ano depois da neurocirurgia, a paciente já está no terceiro ciclo de quimioterapia, vai fazer radioterapia e o seu prognóstico é sombrio, pois o seu tumor que era estritamente orbitário foi transformado em para-meníngeo pelo equivocado encaminhamento do caso.
Até quando oftalmologistas brasileiros vão continuar encaminhado patologias orbitárias a neurocirurgiões? O caso relatado nessa carta não é único. Tenho conversado com outros oftalmologistas que operam órbitas e todos têm experiências semelhantes.

Acho que o Conselho Brasileiro de Oftalmologia além de ser um órgão de defesa de classe, tem responsabilidades na formação continuada dos oftalmologistas brasileiros. A órbita é um tema abandonado pelo Conselho pois a cada congresso nacional de oftalmologia escolhe temas ligados unicamente ao bulbo ocular.

Dessa maneira, enquanto a oftalmologia brasileira caminha cada vez mais para se tornar uma forma sofisticada de optometria, os doentes com problemas orbitários sofrem por falta de educação médica da classe.

Antonio Augusto Velasco e Cruz

Prof. Associado, Chefe do Setor de Órbita, Pálpebras e Vias Lacrimais do Hospital das Clínicas da Faculdade de Medicina de Ribeirão Preto - USP

Anápolis, 8 de janeiro de 2005

Caro Prof. Harley

Gostaria de cumprimentá-lo por seu brilhante artigo "Refratometria ou Optometria" no último número dos Arquivos.

Você conseguiu abordar um tópico que poucas vezes é lembrado nas nossas infindáveis discussões com os Ópticos e outros do gênero. Muitas vezes são faladas coisas como reserva de mercado, corporativismo, soberania dos médicos, dentre outras, mas esta sua argumentação deixa bem claro nosso ponto de vista (trocadilhos à parte...)

Mais uma vez meus parabéns pela sua publicação, e pela forma como vem conduzindo os nossos Arquivos.

Sérgio Godoy

Anápolis - GO

São Paulo, 12 de janeiro de 2005

Ilmos. Srs.

Drs. Harley Bicas e Elisabeto R. Gonçalves

Caros Harley e Elisabeto,

Gostei muito do Editorial sobre Refratometria e Optometria. Vocês levantaram a questão de forma adequada e realista, direcionando-nos a proscrever definitivamente o termo de Optometria na prática médica e oftalmológica.

Em meus 45 anos de formado e militando na vida universitária, sempre passei aos residentes que o termo Optometria é espúrio, 